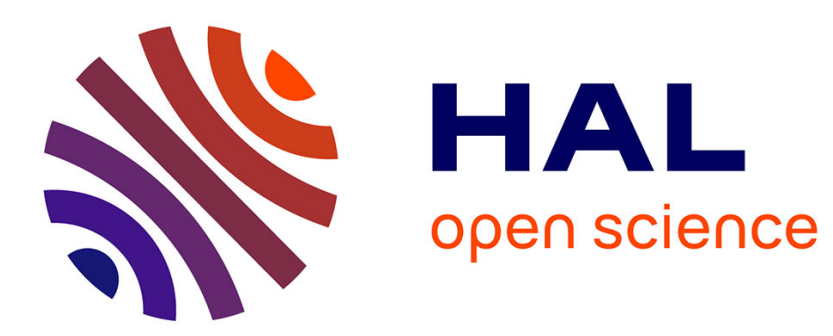

\title{
Improvements in the manufacture of CdTe gamma ray detectors
}

\author{
S. Brelant, M. Elliott, G. Entine, S. Hsu
}

\section{To cite this version:}

S. Brelant, M. Elliott, G. Entine, S. Hsu. Improvements in the manufacture of CdTe gamma ray detectors. Revue de Physique Appliquée, 1977, 12 (2), pp.141-146. 10.1051/rphysap:01977001202014100 . jpa-00244133

\section{HAL Id: jpa-00244133 https://hal.science/jpa-00244133}

Submitted on 1 Jan 1977

HAL is a multi-disciplinary open access archive for the deposit and dissemination of scientific research documents, whether they are published or not. The documents may come from teaching and research institutions in France or abroad, or from public or private research centers.
L'archive ouverte pluridisciplinaire HAL, est destinée au dépôt et à la diffusion de documents scientifiques de niveau recherche, publiés ou non, émanant des établissements d'enseignement et de recherche français ou étrangers, des laboratoires publics ou privés. 


\title{
IMPROVEMENTS IN THE MANUFACTURE OF CdTe GAMMA RAY DETECTORS
}

\section{S. BRELANT}

The Aerospace Corporation, P. O. Box 92957, Los Angeles, California 90009, U. S. A.

\author{
M. ELLIOTT, Capt., USAF
}

Space and Missile Systems Organization

Los Angeles Air Force Station, Los Angeles, California 90009, U. S. A.

\section{G. ENTINE and S. HSU}

Radiation Monitoring Devices, Inc., 6 Silver Lake Avenue, Newton, Massachusetts 02158, U. S. A.

\begin{abstract}
Résumé. - Des progrès notables ont été accomplis dans la qualité des cristaux de tellurure de cadmium dopés au chlore et préparés par la méthode de croissance en solvant THM. De plus, on a pu réduire considérablement les écarts de propriétés d'une tranche à l'autre d'un même lingot et une meilleure reproductibilité d'un lingot à l'autre. Nous pensons que ces progrès sont liés à une amélioration du contrôle des températures dans les fours de tirage.
\end{abstract}

Abstract. - Significant improvements have been made in the quality of chlorine-doped CdTe crystals manufactured by the traveling heater method (THM). In addition, a marked reduction in the variation among ingots and within each ingot has been observed. These results were achieved by modifying the temperature control equipment for the crystal growth process.

1. Introduction. - One of the unique applications of CdTe gamma ray detectors has been the continuous measurement of ablating materials in a hyperthermal environment. Utilization of CdTe for this purpose was described in a paper which was recently presented to the Nuclear Science Symposium of the Institute of Electronic and Electrical Engineers $\left({ }^{1}\right)$. However, the CdTe detector must meet a combination of spectral response, leakage current, and noise criteria to be useful for this application. Table I, based on these criteria,

(1) Clarence Droms, et al., "Heatshield Ablation Sensor Utilizing CdTe Gamma Detectors », IEEE Transactions on Nuclear Science, Vol. NS-23, Nº. 1, February 1976 (p. 498). shows six categories of performance which indicate the overall quality of a CdTe detector.

Before process improvements were accomplished, uniformity within and among CdTe ingots was poor, with only one or two of the twenty-two 2-mm discs sliced from an ingot meeting the required quality standards. (Figure 1 shows the category profile of three typical early ingots; note the small size of the region in which useful properties were found.) As a result, it was necessary to manufacture large quantities of ingots in order to supply the limited number of detectors required for flight programs. Accordingly, a study program was initiated by the U. S. Air Force to examine process parameters with the objective of improving the quality

TABLE I

Detector Categories

\begin{tabular}{|c|c|c|c|c|}
\hline Category & $\begin{array}{c}\text { Maximum } \\
\text { current } \\
(60 \mathrm{~V})(\mu \mathrm{A})\end{array}$ & $\begin{array}{c}\text { Maximum } \\
\text { noise } \\
(\mathrm{keV})\end{array}$ & $\begin{array}{c}\text { Minimum } \\
\text { resolution } \\
\mathrm{Co}^{57} \text { spectrum }\end{array}$ & $\begin{array}{l}\text { Possible } \\
\text { Application }\end{array}$ \\
\hline 1 & 0.300 & 20 & A & Spectroscopic detector \\
\hline 2 & 0.350 & 20 & B & Flight detector \\
\hline 3 & 0.350 & 30 & B & Low energy counter \\
\hline 4 & - & 40 & C & High energy counter \\
\hline 5 & - & 50 & D & High dose counter \\
\hline 6 & - & - & F & Mechanical sample \\
\hline
\end{tabular}



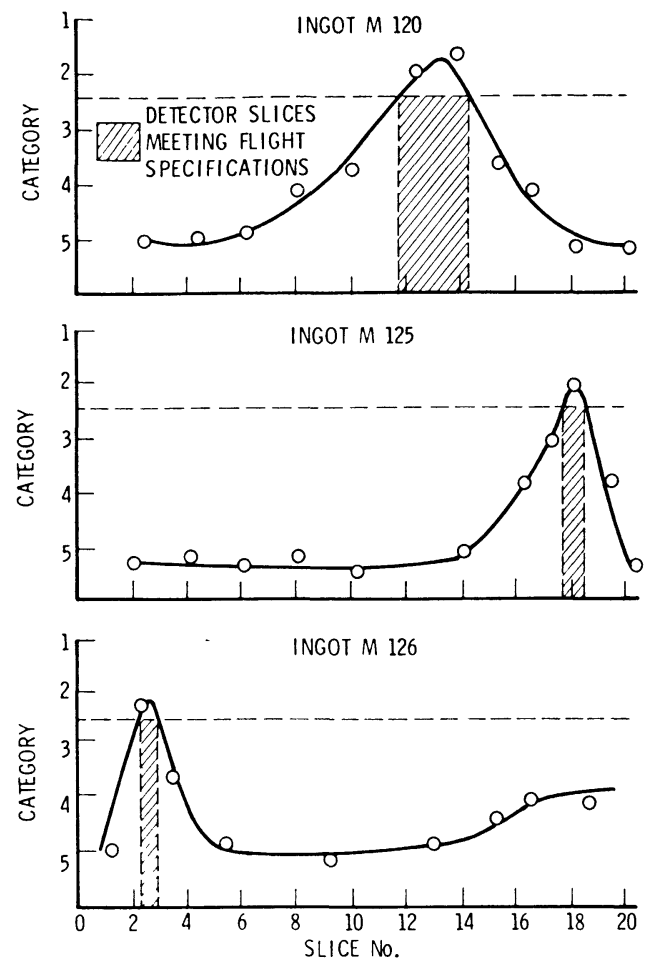

FIG. 1. - Three typical early ingots which produced usable detectors.

of CdTe crystal detectors. This paper describes the process modifications which produced ingots with long regions of high, uniform quality, each capable of yielding 10 or more usable detector slices.

2. Review of the manufacturing process. - Before discussing the process modifications studied in the program, the steps (formation, purification, and doping) employed in manufacturing $\mathrm{CdTe}$ crystals in 1-cm diameter quartz ampules will be reviewed.

2.1 Formation. - The reaction step of $\mathrm{Cd}$ and $\mathrm{Te}$ begins when the two elements are melted in the quartz ampule at temperatures of $300^{\circ} \mathrm{C}$ to $500^{\circ} \mathrm{C}$. The liquid elements are then mechanically mixed and slowly brought to $900^{\circ} \mathrm{C}$ where compound formation occurs. The solid precipitant is relatively inhomogeneous and porous.

The ampule is then transferred to a high-temperature furnace where the $\mathrm{CdTe}$ is melted at $1200^{\circ} \mathrm{C}$. The molten ingot, lowered out of the furnace over a period of two days, solidifies into a single crystal.

Because some impurities from the quartz are introduced during this high-temperature process, a lowertemperature crystal-purification step is needed.

2.2 Purification. - The traveling heater method (THM), a process in which the crystal is dissolved and precipitated out of a Te solvent zone, is used in the purification step. The purification ampule contains the Te zone at the bottom and the ingot of CdTe from the high-temperature formation step at the top. Heat is applied to the zone by an RF generator which couples inductively to the low-resistivity $\mathrm{Te}$. The heated Te dissolves enough CdTe to become fully saturated.

As the ampule is lowered through the heater, the bottom end of the zone becomes cooler and CdTe precipitates out. The top of the zone, being hotter, dissolves more CdTe from the feed ingot, continuing the process. When the ampule has completed its passage through the heater, the solid, purified polycrystalline CdTe will be on the bottom and the Te zone, containing most of the impurities, will be on the top. The THM process is illustrated in figure 2.

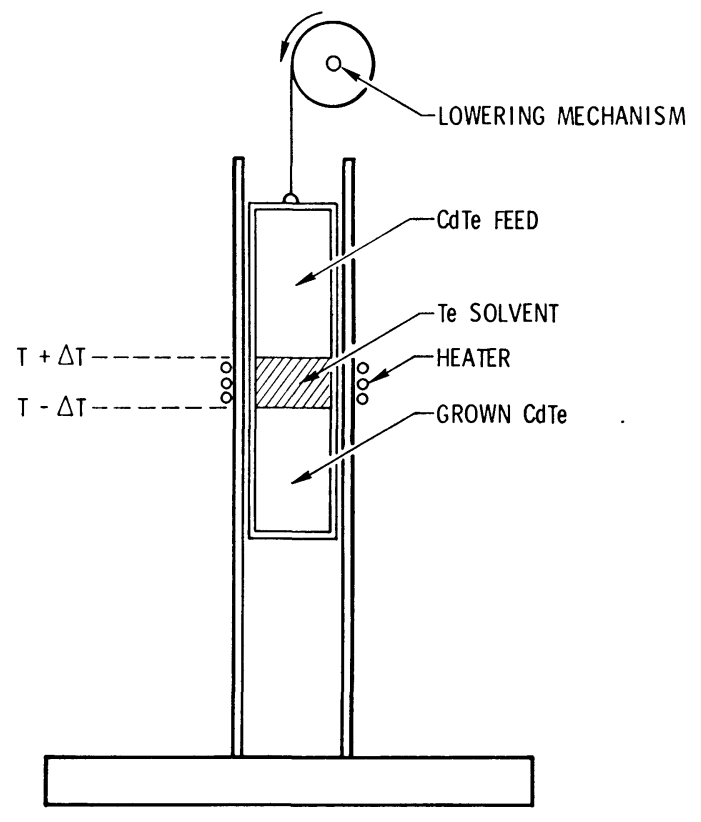

FIG. 2. - Schematic of THM process.

2.3 Doping. - Doping, the final process, is similar to the previous step. However, the heat is provided by a resistance-heated element which should be accurately temperature controlled. Approximately three weeks are required to achieve the desired homogeneity and to complete the doping process. When doping has been completed, the CdTe ingot is ready to be sliced into twenty-two $2-\mathrm{mm}$ thick discs for use as detectors.

3. Improvements in the process control. - The first step in the evaluation of CdTe crystals is a microscopic examination using IR light $(\lambda>8000 \AA)$ transmitted from a tungsten source. Transparent in the IR, CdTe will transmit the light. Inclusions, which do not transmit the IR, will appear black. Pictures are taken using a Bausch and Lomb binocular microscope at $1 \times$ with a Polaroid Model EO-10 Land camera attached. A nualitative estimate of the Te inclusion densities is then made by eye, either directly or from the photographs. These densities are ranked from clear to heavily included (see Fig. 3). No direct correlation of inclusion density-to-crystal quality could be found. It was 


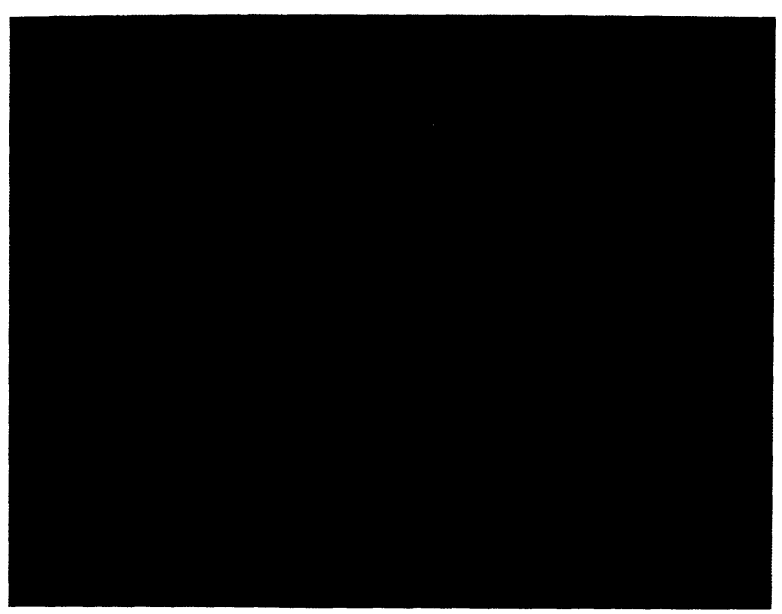

a) Clear CdTe, few Te inclusions.

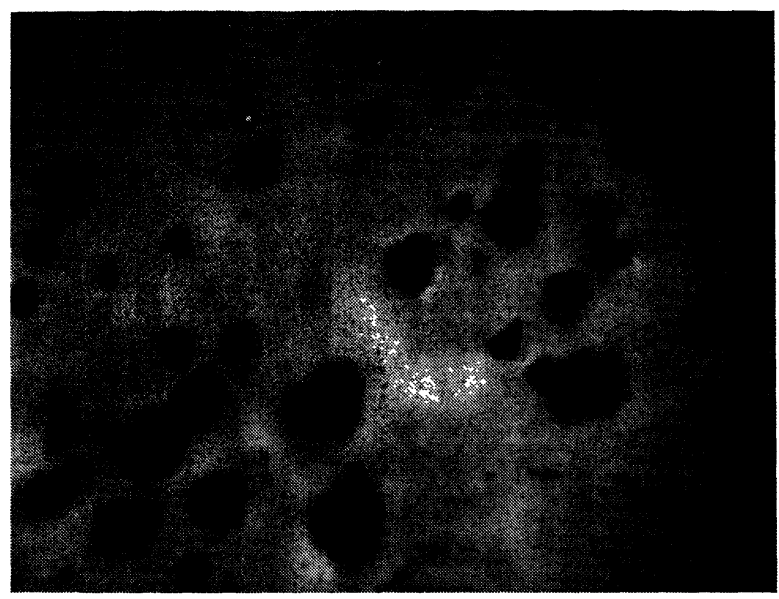

b) Heavily included CdTe.

Fig. 3. - Infrared microscope transmission of CdTe slices showing Te inclusions.

observed, however, that while clear crystals did not necessarily signify good auality, occluded crystals never made good detectors. It appeared obvious that the first improvement in process control had to be the production of crystals without inclusions. Temperature regulation and control during the purification and doping steps, which essentially recrystallize the CdTe, offered the greatest potential for production of clear crystals. Regulation of the purification growth temperature will be discussed first.

3.1 Temperature Regulation OF the PURIFicaTION PROCESS. - As discussed above, the inductionheated THM process serves as a purification step. Because the RF power couples only to the Te zone, the heating is localized enough to cause very active mixing of the molten elements. The mixing allows the CdTe to be quickly transported across the zone, completing the process in only two days. However, the input to the heating coil was set manually and, consequently, subject to gross human error ; temperature variations between operations were as great as $125^{\circ} \mathrm{C}$.

A system was designed to use the blackbody radiance

REVUE DE PHYSIQUe APPLIQUÉE. - T. 12, No 2, FÉVRIER 1977 of the Te zone as the means of both monitoring and controlling the temperature of the process. A threefoot quartz-tipped light pipe, focused onto the incandescent Te zone, carries the light to a phototransistor inside a shielded amplifier. The first stage of the amplifier provides a metered output which is proportional to the light signal. This output can be calibrated, by means of an optical pyrometer, to the temperature of the zone and used to set the desired point for regulation. The second stage of the amplifier contains a differential circuit which compares the photosignal to a voltage determined by the operator and is the means of setting the temperature. The amplifier drives an SCR voltage controller which is in series with the secondary winding of the variac driving the induction furnace. The temperature can be held to within $\pm 10^{\circ} \mathrm{C}$ without oscillation This system, in daily use for several months, has proven extremely reliable, convenient, and stable.

3.2 Redesign of THM fURNACES. - The most important crystal growth step in the production of CdTe for gamma ray detection is the final doping THM process. This process, which requires approximately three weeks per ingot, determines both the ultimate crystallinity and resistivity of the detector slice. In this step, a crucial growth parameter is the heater temperature which is nominally between $700{ }^{\circ} \mathrm{C}$ and $925^{\circ} \mathrm{C}$. Although the temperature sensors are designed to regulate to $\pm 1^{\circ} \mathrm{C}$, optical pyrometer measurements indicated that the temperature variation among the ten furnaces was over $80^{\circ} \mathrm{C}$.

This major source of temperature variation resulted from improper design and mounting of the thermocouples in the heater ring. The original furnace designs consisted of nickel rings of various aspect ratios, each containing a $4 \mathrm{~mm}$-deep hole for a thermocouple.

The design and mounting deficiencies were corrected and the furnaces rebuilt. The furnaces now contain calibrated inconel-shielded thermocouples manufactured by the Omega Corporation. The $10 \mathrm{~mm}$-diameter shields not only reduce the amount of electrical pickup which must be overcome, but more importantly, reduce the rate of sensor deterioration and provide a means for uniform thermal contact.

The new heater rings, made of nickel 200, contain accurately located holes $2 \mathrm{~mm}$ in diameter which extend half the length of the cylinder. The thermocouples are bonded into these holes with Omega hightemperature cement which provides a large area of good thermal contact. By placing the thermocouples deep within the rings, enough lead wire is maintained at the ring temperature to avoid heat leaks.

Calculations show that the temperature gradient along the nickel ring is, at most, $\pm 4{ }^{\circ} \mathrm{C}$, and between the outer and inner surfaces, only $\pm 2{ }^{\circ} \mathrm{C}$. With the thermocouple holes being positioned within $2.5 \mathrm{~mm}$ along the radius, and $0.5 \mathrm{~mm}$ along the axis, the temperature error due to the thermocouple placement is less than $\pm 0.5^{\circ} \mathrm{C}$. 


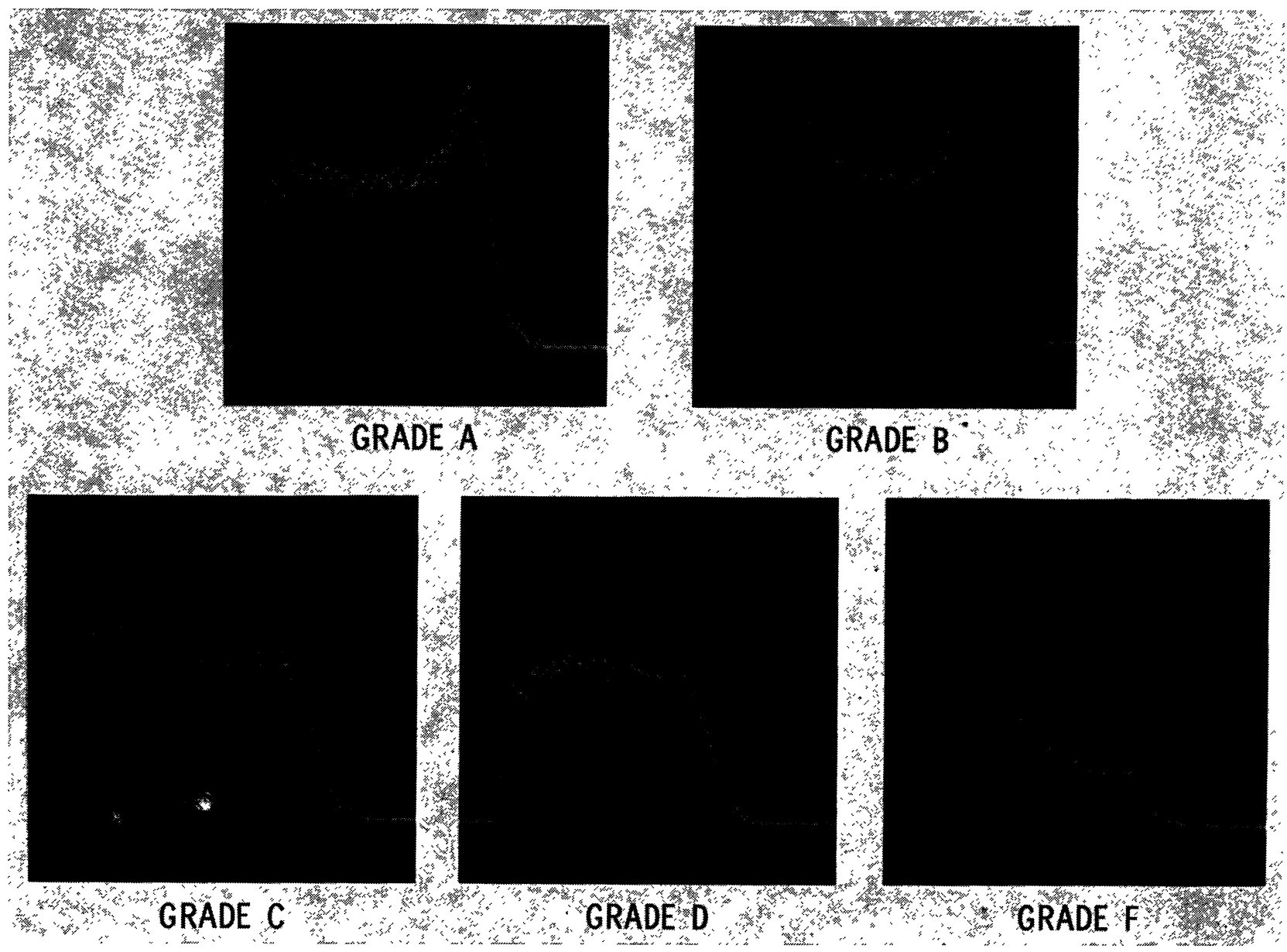

FIG. 4. - $\mathrm{Co}^{57}$ Spectra, Grades A to F.

Within the accuracy of the hot-wire optical pyrometer used, no variation among the furnaces could be detected.

4. Ingot evaluation. - In addition to the microscopic examination of each disc described earlier, five discs were fabricated into detectors. The detectors were then scan-tested on a pulse height analyzer for leakage current, noise, and spectral response. The $50 \mathrm{M} \Omega$ bias resistor was adjusted to ensure that the actual voltage across the detector was always $60 \mathrm{~V}$, irrespective of the leakage current. Noise was measured by raising the discriminator threshold level until no more than two counts per second were observed. No correction was made for the $7 \mathrm{keV}$ noise of the preamplifier.

Spectra are evaluated within grades (from A to F) according to the $\mathrm{Co}^{57}$ peak-to-valley ratio. Figure 4 shows representative spectra of each grade. Experience shows that detectors with spectra of A or B have a high probability of passing flight sensor count-rate tests. These electrical tests supply the data for the categories which are utilized to describe the achievements of the program.

5. Evaluation of improvements in ingot uniformity. 5.1 INGOT UNIFORMITY AT START OF PROGRAM. -
Before the present study, the uniformity within and among ingots was quite low, necessitating production of large quantities of ingots to obtain only a few usable detectors. Large detectors, such as the slab detectors now under consideration $(1.5 \mathrm{~cm} \times 7.5 \mathrm{~mm} \times 2.5 \mathrm{~mm})$ for increased count rate efficiency, were impractical. Table II $a$ shows the average performance of ingots grown during the early part of the program. A depressingly large percentage of the ingots had very high leakage current throughout the crystal. Many ingots were lost during crystal growth and could not be evaluated. Usable detectors were obtained primarily from small regions of a few ingots.

Occasionally, a so-called super ingot was found from which as many as 10 detector candidates could be made. The existence of such ingots was the basis for the belief that the overall process could be made reliable and reproducible.

5.2 INGOT UNIFORMITY AT CONCLUSION OF PROGRAM. - By the end of the program, a truly dramatic improvement in crystal quality was observed (see Table II $b$ ). The percentage of usable ingots is much higher and the uniformity within all the ingots (even those of poor quality) is much better. While there is still some variation within an ingot, the parameters tend to change 
TABLE II

Comparison of quality of ingots grown during early and late stages of the program

a) Ingots grown early in program

\begin{tabular}{|c|c|c|c|c|c|c|c|c|c|c|c|c|c|c|}
\hline & \multicolumn{14}{|c|}{ Ingot No. } \\
\hline & 89 & 90 & 91 & 92 & 95 & 96 & 99 & 104 & 119 & 120 & 123 & 124 & 125 & 126 \\
\hline & - & - & 一 & - & - & - & - & - & - & - & - & - & - & - \\
\hline ate & 6 & 5 & 5 & 6 & 5 & 6 & 5 & 6 & 6 & 4 & 6 & 1 & 3 & 4 \\
\hline Leakage $(60 \mathrm{~V})(\mu \mathrm{A})$ & $\mathrm{X}$ & 0.87 & 0.83 & $\mathrm{X}$ & 0.95 & 0.70 & 0.37 & $\mathrm{X}$ & 0.28 & 0.28 & $\mathrm{X}$ & 0.28 & 0.30 & 0.20 \\
\hline Spectrum $\mathrm{Co}^{57}$ & F & $\mathrm{D}$ & D & $\mathrm{F}$ & D & $\mathrm{D}$ & $\mathrm{D}$ & $\mathrm{F}$ & $\mathbf{F}$ & $\mathrm{C}$ & F & $\mathbf{A}$ & B & $\mathrm{C}$ \\
\hline
\end{tabular}

b) Ingots grown late in program

\begin{tabular}{|c|c|c|c|c|c|c|c|c|c|c|c|c|c|c|}
\hline & \multicolumn{14}{|c|}{ Ingot No. } \\
\hline & 139 & 140 & 141 & 142 & 143 & 144 & 148 & 153 & 154 & 155 & 156 & 161 & 162 & 163 \\
\hline & - & - & - & - & - & - & - & - & - & - & - & - & - & - \\
\hline Category & 3 & 2 & 4 & 2 & 3 & 1 & 1 & 2 & 3 & 5 & 1 & 1 & 2 & 1 \\
\hline Leakage $(60 \mathrm{kV})(\mu \mathrm{A})$ & 0.20 & 0.25 & 0.50 & 0.30 & 0.30 & 0.25 & 0.25 & 0.30 & 0.30 & 0.60 & 0.25 & 0.25 & 0.25 & 0.25 \\
\hline Spectrum $\mathrm{Co}^{57}$ & B & B & B & B & B & A & A & B & B & D & A & A & B & A \\
\hline
\end{tabular}

smoothly, indicating that these variations may result from chemical inconsistencies rather than from the temperature fluctuations experienced before the furnaces were redesigned and rebuilt. Figure 5 shows the
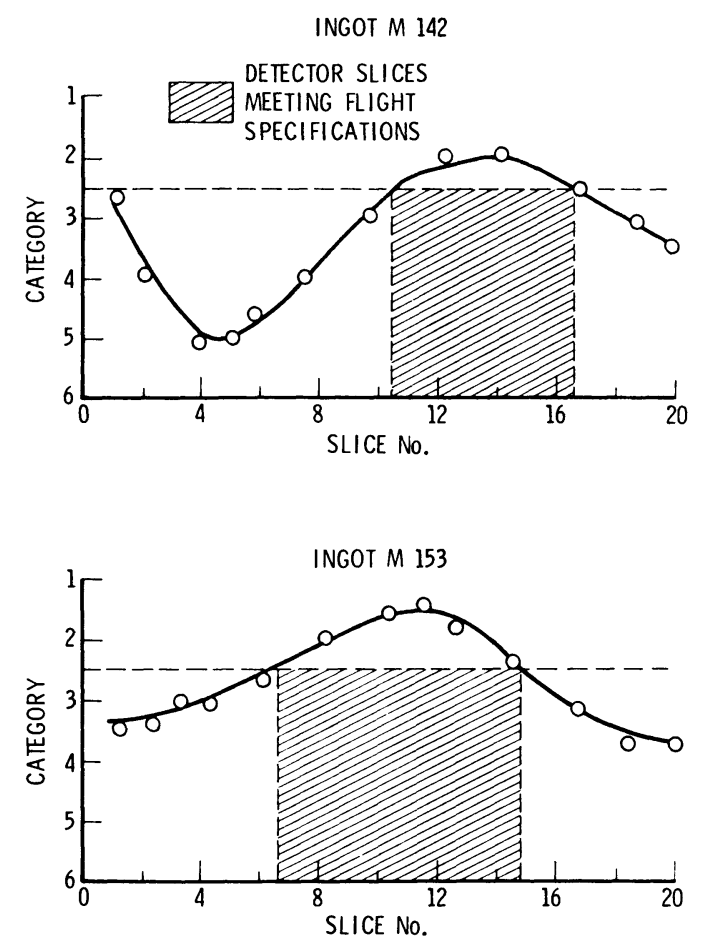

FIG. 5. - Characteristics of typical recent ingots.

detector category as a function of slice number for two typical recent ingots. Note the distinct trend toward category 4 or 5 in the first half of Ingot M 142 and the uniformly category 2 or 3 qualities over much of the second half. Both of these ingots would probably have produced useful slab detector candidates had they been sliced with that objective in mind.
Figure $6 a$ shows the leakage current versus slice number for a recent ingot. In this example, the ingot is uniform over an even greater length. Figure $6 b$ shows how this uniformity in leakage current (and other parameters) translates into much better overall detector quality along the ingot.

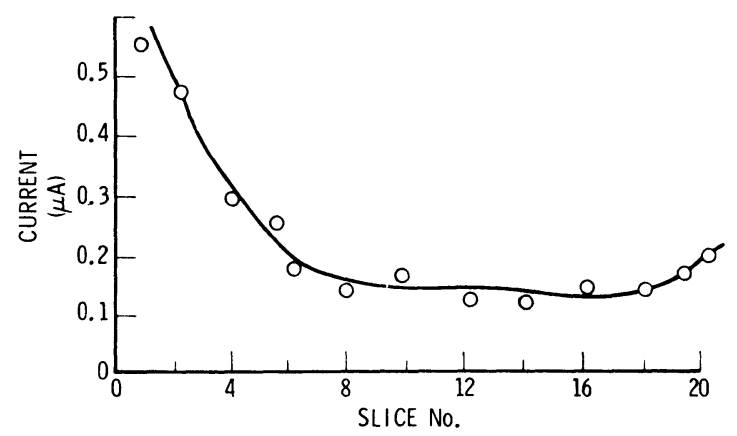

a. LEAKAGE CURRENT VS SLICE NUMBER

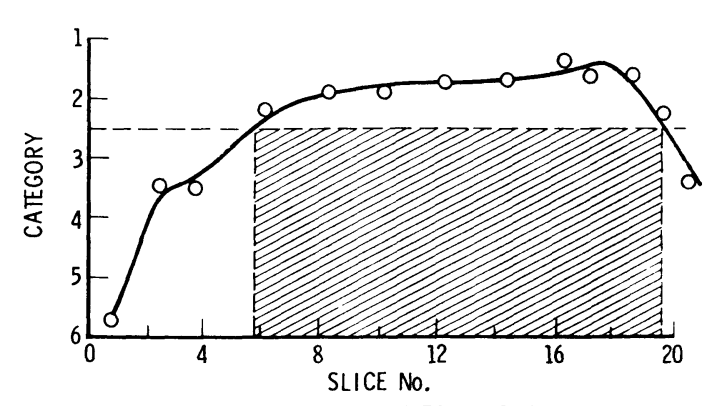

b. UNIFORMITY OF DETECTOR QUALITY

FIG. 6. - Characteristics of the best recent ingot.

Figure 7 shows the average category of the five best detectors of each ingot grown during the contract period. It is evident that better material handling and improved temperature regulation of the purification 


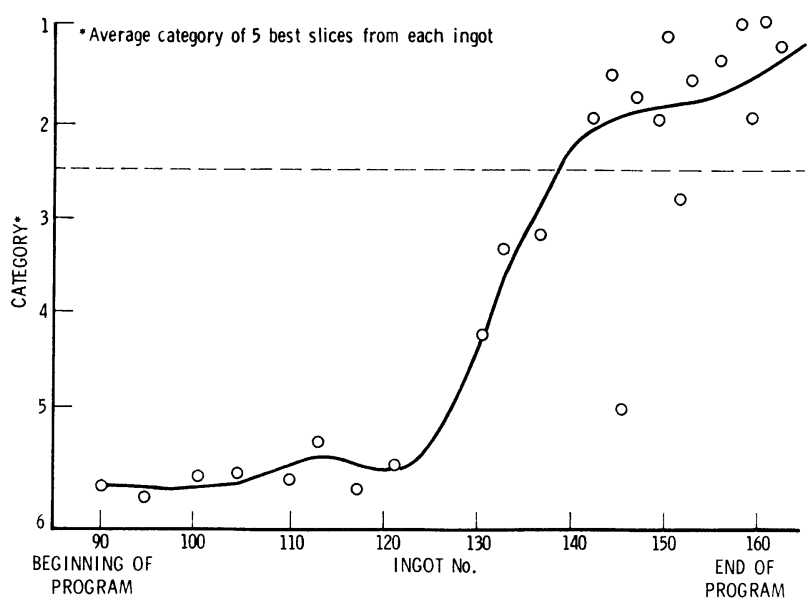

FIG. 7. - Quality of crystals improved during program.

and dopant furnaces during the crystal growth process resulted in a dramatic improvement in detector quality.

Crystal uniformity also improved during the course of the program. The combination of better average quality plus better uniformity should lead directly to large, more sensitive (slab) detectors.

6. Conclusions. - The yield of CdTe ingots with long regions of uniform high quality has been increased sufficiently that production of rectangular slab detectors can be seriously considered. The improved quality detectors should prove beneficial to a great variety $o$ applications. Further, the ability to produce uniform, high quality crystals will accelerate the development $o$ new detector electrode techniques which will lead directly to significant improvements in energy resolution.

Considerable development work on $\mathrm{CdTe}$ detectors remains to be done, including optimization of crystal growth conditions, growth of large ingots, and improvement of detector electrodes.

Acknowledgement. - The authors wish to acknowledge the support of the Space and Missile Systems Organization, Los Angeles Air Force Station, Los Angeles, California, which made this study possible. 